\title{
Cardiopulmonary Exercise Testing in Patients with Asymptomatic or Equivocal Symptomatic Aortic Stenosis: Feasibility, Reproducibility, Safety and Information Obtained on Exercise Physiology
}

\author{
Douet van Le Gunnar Vagn Hagemann Jensen Steen Carstensen \\ Lars Kjøller-Hansen
}

Department of Cardiology, Roskilde University Hospital, Roskilde, Denmark

\begin{abstract}
Key Words
Cardiopulmonary exercise testing · Aortic valve area .

Aortic stenosis
\end{abstract}

\begin{abstract}
Objective: The aim of this study was to determine the feasibility, reproducibility, safety and information obtained on exercise physiology from cardiopulmonary exercise testing (CPX) in patients with aortic stenosis. Methods: Patients with an aortic valve area (AVA) $<1.3 \mathrm{~cm}^{2}$ who were judged asymptomatic or equivocal symptomatic underwent CPX and an inert gas rebreathing test. Only those where comprehensive evaluation of CPX results indicated haemodynamic compromise from aortic stenosis were referred for valve replacement. Results: The mean patient age was $72( \pm 9)$ years; an AVA index $<0.6 \mathrm{~cm}^{2} / \mathrm{m}^{2}$ and equivocal symptomatic status were found in 90 and $70 \%$, respectively. CPX was feasible in 130 of the 131 patients. The coefficients of repeatability by test-retest were $5.4 \%\left(\mathrm{pVO}_{2}\right)$ and $4.6 \%$ (peak $\mathrm{O}_{2}$ pulse). A $\mathrm{pVO}_{2}<83 \%$ of the expected was predicted by a lower stroke volume at exercise, lower peak heart rate and $\mathrm{FEV}_{1}$, and higher VE/ $/ \mathrm{VO}_{2}$, but not by AVA index. Equivocal symptomatic status and a low gradient but high valvulo-arterial impedance were associated with a lower $\mathrm{pVO}_{2}$, but not with an in-
\end{abstract}

ability to increase stroke volume. In total, 18 patients were referred for valve replacement. At 1 year, no cardiovascular deaths had occurred. Conclusions: CPX was feasible and reproducible and provided comprehensive data on exercise physiology. A CPX-guided treatment strategy was safe up to 1 year.

(c) 2015 S. Karger AG, Basel

\section{Introduction}

Symptomatic aortic stenosis is considered a class I indication for aortic valve replacement (AVR) [1]. However, determining whether a patient is symptomatic from aortic stenosis is often complicated and ambiguous. When patients with aortic stenoses become symptomatic, the most frequent symptom is dyspnoea or functional limitation $[2,3]$. However, this symptom may have causes other than aortic stenosis, including deconditioning, a sedentary lifestyle, obesity, comorbidity or aging. On the other hand, symptoms may be concealed by adaptation to a more sedentary lifestyle. Exercise testing is recommended in cases of equivocal symptomatic aortic stenosis [1], but is of limited value in patients aged more than 70 years or in functional class II [3]. In addition, the positive

\section{KARGER}

E-Mail karger@karger.com

www.karger.com/crd
(C) 2015 S. Karger AG, Basel

$0008-6312 / 15 / 1333-0147 \$ 39.50 / 0$
Lars Kjøller-Hansen

Department of Cardiology, Roskilde Hospital

Køgevej 7-13

DK-4000 Roskilde (Denmark)

E-Mail lak@ regionsjaelland.dk 
predictive value of symptoms revealed during exercise tests for progression to valve replacement is only $50 \%$ [3]. Furthermore, such predictive values may be inflated by knowledge of the test results [4]. When aortic stenosis is the culprit of a patient's symptoms, the underlying pathophysiology typically includes the inability to increase or maintain stroke volume, which reduces cardiac output and oxygen delivery during exercise $[2,5]$. During cardiopulmonary exercise testing (CPX), a number of cardiorespiratory parameters are measured, including peak oxygen consumption $\left(\mathrm{pVO}_{2}\right)$ and peak oxygen pulse $\left(\mathrm{pO}_{2}\right.$ pulse), which reflect cardiac output and stroke volume, respectively. These measurements often facilitate a more detailed assessment of the cause of a functional limitation [6]. Determining cardiac output during exercise via inert gas rebreathing (IGR) is promising in patients with heart failure or aortic stenoses [5, 7]. Cardiac output and stroke volume, as assessed by either $\mathrm{pVO}_{2}$ and $\mathrm{pO}_{2}$ pulse or IGR during exercise, are of great pathophysiological importance in patients with aortic stenoses. However, few studies have addressed this topic.

The purpose of this study was to evaluate the feasibility, reproducibility and results of CPX in patients with asymptomatic or equivocal symptomatic aortic stenoses who are difficult to assess. This includes those aged more than 70 years, those with a peak flow velocity across the aortic valve (Vmax) of less than $4 \mathrm{~m} / \mathrm{s}$ and high valvuloarterial impedance (Zva), those with a Vmax greater than $5 \mathrm{~m} / \mathrm{s}$, those classified as New York Heart Association (NYHA) II or III, those with chronic obstructive pulmonary disease (COPD), and those with symptoms, impaired blood pressure responses or ST depression during exercise tests. We also aimed to determine the predictors of decreased $\mathrm{pVO}_{2}$ and to assess the safety of using comprehensive evaluation of CPX results to determine haemodynamic compromise and treatment strategies in such patients.

\section{Methods}

\section{Patients}

The study population was recruited from patients referred to the outpatient clinic of the Cardiology Department at Roskilde University Hospital from 1 March, 2010, to 1 October, 2011. Following a clinical and echocardiographic evaluation by a cardiologist, patients who were deemed to be asymptomatic or equivocal symptomatic from known or newly diagnosed moderate or severe aortic stenoses [aortic valve area (AVA) $\leq 1.3 \mathrm{~cm}^{2}$ ] were invited to participate in the study. Patients who exhibited a left ventricular ejection fraction less than 50\%, who had atrial fibrillation with a resting heart rate greater than $90 \mathrm{bpm}$, who had more than trivial valvular disease of any other kind, or who were deemed unable to perform the bicycle ergometer test because of neurological or orthopaedic causes were not eligible.

All patients underwent a clinical history examination, NYHA functional classification, echocardiography and measurement of brain natriuretic peptide (BNP) before the CPX with IGR.

At 12 months, the survival status of all patients was recorded from the National Patient Registry; the cause of death was defined as the primary diagnosis in the discharge summary. All included patients provided written informed consent, and the study was approved by the local ethics committee (1-01-83-0002-07).

\section{CPX with IGR}

CPX was performed on an upright bicycle ergometer with breath-by-breath measurement of oxygen consumption $\left(\mathrm{VO}_{2}\right)$, carbon dioxide exhaustion $\left(\mathrm{VCO}_{2}\right)$ and minute ventilation (VE), and continuous heart rate and ECG monitoring using Innovision version 6.15 (Innocor; Odense, Denmark). For each patient, the load was calculated and set to reach the predicted $\mathrm{pVO}_{2}$ in approximately $8-10 \mathrm{~min}$, with linear increments in load at $1-\mathrm{min}$ intervals after $3 \mathrm{~min}$ of unloaded cycling [6]. Thus, the exercise time and the watts achieved are not relevant. Symptoms, such as more than usual exertional dyspnoea, dizziness and angina, were recorded. The stopping criteria included exhaustion and symptom limitation. The key measures obtained during $\mathrm{CPX}$ were $\mathrm{pVO}_{2}$, expressing cardiac output; $\mathrm{pO}_{2}$ pulse $\left(\mathrm{pVO}_{2} /\right.$ heart rate), expressing stroke volume; the respiratory coefficient $\left(\mathrm{R}=\mathrm{VCO}_{2} / \mathrm{VO}_{2}\right.$ at peak/end exercise), which when less than 1 suggests inadequate effort or non-physiological hyperventilation, and the $\mathrm{VE} / \mathrm{VCO}_{2}$ nadir after the anaerobic threshold, which when high indicates ventilatory/flow mismatch. The anaerobic threshold was determined using the V-slope method. An estimated stroke volume at peak exercise was obtained by $\mathrm{pO}_{2}$ pulse/haemoglobin $(\mathrm{Hb}) \times 100$ and indexing for body surface area (i.e. $\mathrm{pO}_{2}$ pulse/ $\mathrm{Hb}$ index) because $\mathrm{Hb}$ in grams per decilitre corresponds to the oxygen extraction in millilitres per decilitre [8].

Predicted $\mathrm{pVO}_{2}$ was defined according to the EAPCR/AHA statement $[6,9]$. $\mathrm{A} \mathrm{pVO}_{2}$ less than $83 \%$ of the predicted value (i.e. less than the lower $95 \%$ confidence value in a healthy sedentary population [6]) was regarded as significantly subnormal. The predicted peak heart rate (pHR) was calculated as 220 minus the subject's age in years. The predicted $\mathrm{pO}_{2}$ pulse was calculated as the

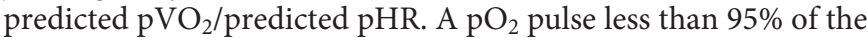
predicted, which corresponds to a $\mathrm{pVO}_{2}$ less than $83 \%$ of the predicted at a pHR of $87 \%$ of the predicted, was considered abnormal. The $\mathrm{O}_{2}$ pulse and $\mathrm{VO}_{2}$ values were plotted against the load to yield trajectories, which were assessed visually for slope and linearity and blinded to other patient data. An abnormal $\mathrm{O}_{2}$ pulse trajectory was defined as one having a plateau starting prior to the third (last) stage or a decline starting prior to the last stage of exercise. An abnormal $\mathrm{VO}_{2}$ trajectory was defined as one having a decrease in slope prior to the last stage of exercise. Spirometry was performed at rest, and the breathing reserve during exercise was defined as: $40 \times$ forced expiratory volume in the first second $\left(\mathrm{FEV}_{1}\right)$ - maximal minute VE [6]. To assess repeatability, 15 patients who lived close to the hospital were retested within 2 weeks.

Cardiac output was assessed using IGR according to Innovision recommendations and the user manual. Patients inspired an oxygen-enriched mixture of an inert soluble gas ( $0.5 \%$ nitrous oxide) and an inert insoluble gas ( $0.1 \%$ sulphur hexafluoride) from a 4 -li- 
tre bag. Respiratory gas concentrations were measured over the next breaths using photoacoustic analysers in this closed system. The concentration of nitrous oxide decreases proportionally with the pulmonary blood flow, which can then be calculated by the Innocor. In the absence of shunts, this measurement corresponds to cardiac output. The IGR method was used at rest and during submaximal exercise beyond the anaerobic threshold, which is the point of maximal stroke volume during exercise. The stroke volume index (SVI) was calculated at rest and during exercise (SVIrest and SVI-exercise) from the cardiac output, heart rate and body surface.

\section{Echocardiography}

All patients underwent two-dimensional and Doppler echocardiography (General Electric Vivid E9; GE Healthcare, Horten, Norway). Apical continuous wave and pulsed wave Doppler recordings across the aortic valve were created to obtain the Vmax, mean pressure gradient from the velocity time integral, ventricular outflow velocity time integral and early diastolic inflow velocity (E). The left ventricular outflow diameter was measured in the parasternal long-axis view in the mid-systole. The aortic valve areal index was calculated using the continuity equation and indexed for body surface. The left ventricular ejection fraction was estimated visually from several two-dimensional projections. Pulsedtissue Doppler recordings were made from the apex to obtain the early lateral mitral annulus velocity $\left(\mathrm{e}^{\prime}\right)$, and $\mathrm{E} / \mathrm{e}^{\prime}$ was calculated as an expression of diastolic pressure. Left ventricular systolic function was assessed using the peak systolic tissue velocity ( $\mathrm{Sa}$ ) derived from apical colour tissue Doppler recordings of the mitral annulus because it is a more sensitive marker of systolic function in patients with aortic stenoses than the ejection fraction [10]. The mean of the septal and lateral Sa values was calculated.

\section{Valvulo-Arterial Impedance}

Zva was calculated as: systolic blood pressure + mean systolic aortic valve gradient/stroke volume. This was obtained at rest using measurements from sphygmomanometer assessments of brachial blood pressure, from echocardiography and during IGR, respectively. The value was deemed high when it was above the median of the study population, which was $5.5 \mathrm{~mm} \mathrm{Hg} / \mathrm{ml} / \mathrm{m}^{2}$. This value also corresponds to the cut-off value used in a previous important study [11].

\section{Brain Natriuretic Peptide}

To determine BNP, venous blood from the forearm was obtained with the patient in a resting condition. A value above the upper level of normal (BNP > ULN) was determined according to the local laboratory reference including age and gender.

\section{Evaluation of CPX Results}

Haemodynamic compromise from aortic stenosis was primarily defined as $\mathrm{pVO}_{2}$ less than $83 \%$ of the predicted value, $\mathrm{O}_{2}$ pulse less than $95 \%$ of the predicted value and good effort $(\mathrm{R}>1)$. However, when $\mathrm{VE} / \mathrm{VCO}_{2}$ was greater than 32 , but $\mathrm{FEV} \mathrm{V}_{1}$ was normal ( $>80 \%$ of the predicted value) and the breathing reserve was not low (>25), or clear exercise-limiting symptoms (angina, severe dizziness and discomfort, and more than usual dyspnoea) were seen, and the CPX results pointed to no cause other than aortic stenosis, we deemed this to be indicative of haemodynamic compromise. The evaluation of CPX results was performed blinded to the echo-
Table 1. Baseline characteristics $(\mathrm{n}=131)$
Age, years

Male/female ratio

Body mass index

Diabetes mellitus

Hypertension

Smoker

Obstructive lung disease

Prior revascularization

Atrial fibrillation

Pacemaker

Asymptomatic/ equivocal symptomatic

NYHA class I

Creatinine, $\mu \mathrm{mol} / \mathrm{l}$

LDL cholesterol, $\mathrm{mmol} / 1$

BNP > ULN

\section{Echocardiography}

Vmax, $\mathrm{m} / \mathrm{s}$

$V \max >4 \mathrm{~m} / \mathrm{s}$

Mean gradient, $\mathrm{mm} \mathrm{Hg}$

AVA index, $\mathrm{cm}^{2} / \mathrm{m}^{2}$

AVA index $<0.6 \mathrm{~cm}^{2} / \mathrm{m}^{2}$

Left posterior wall thickness, $\mathrm{cm}$

$\mathrm{Sa}, \mathrm{cm} / \mathrm{s}$

$\mathrm{E} / \mathrm{e}^{\prime}$

Cardiovascular drugs

$\beta$-Blockers

Digoxin

ACE-/AT-II inhibitors

Diuretics

Calcium-blockers

Statins
$\mathrm{Hb}, \mathrm{mmol} / \mathrm{l}$
$72.1 \pm 9.3$
$83 / 48$
$26.8 \pm 4.0$
$16(12)$
$78(60)$
24 (18)
$21(16)$
$13(10)$
$16(12)$
4 (3)
$38 / 92(29.2 / 70.8)$
$68(52)$
$8.8 \pm 0.7$
$82.9 \pm 20.0$
$2.96 \pm 0.98$

35 (26.7)

$3.92 \pm 0.77$

$55(42.3)$

$38.2 \pm 15.3$

$0.45 \pm 0.11$

$117(90.0)$

$1.14 \pm 0.25$

$5.00 \pm 1.23$

$13.3 \pm 5.0$

$36(28)$

$9(7)$

$47(36)$

$51(39)$

$37(28)$

$74(56)$
Values are presented as $\mathrm{n}(\%)$ and mean \pm SD.

cardiographic severity of the aortic stenosis, whereas the assessment of symptoms during CPX was not. When CPX indicated haemodynamic compromise from the aortic stenosis, the patient was referred for an angiogram and evaluation for AVR by an independent heart team who had no knowledge of the details of the CPX results.

\section{Statistics}

The SPSS Statistics 20 software program (IBM, New York, N.Y., USA) was used for statistical calculations. Continuous variables are presented as the mean and standard deviation (SD). A normality plot was used to assess skewness. An unpaired t test was used to compare the means of two groups. Categorical variables are presented as numbers and percentages. The coefficient of variability was calculated as the SD of the mean difference between the test and retest results divided by the mean value of the two tests. The Fisher exact test was used to find between-group differences in categorical variables. Using logistic regression, we found predic- 
Table 2. Characteristics and CPX results in those referred as asymptomatic versus equivocal symptomatic

\begin{tabular}{|c|c|c|c|}
\hline & $\begin{array}{l}\text { Asymptomatic } \\
(\mathrm{n}=38)\end{array}$ & $\begin{array}{l}\text { Equivocal symptomatic } \\
(\mathrm{n}=92)\end{array}$ & $\mathrm{p}$ value \\
\hline $\mathrm{pVO}_{2}<83 \%$ predicted & $4(10.5)$ & $30(32.6)$ & 0.009 \\
\hline $\mathrm{pVO}_{2}, \%$ predicted & $104.1 \pm 19.5$ & $93.7 \pm 22.3$ & 0.014 \\
\hline $\mathrm{pO}_{2}$ pulse, $\%$ predicted & $113.5 \pm 20.0$ & $106.9 \pm 25.1$ & 0.15 \\
\hline $\mathrm{pO}_{2}$ pulse $/ \mathrm{Hb}$ index, $\mathrm{ml} / \mathrm{m}^{2}$ & $47.8 \pm 8.5$ & $42.3 \pm 8.7$ & 0.001 \\
\hline $\mathrm{R}$ & $1.06 \pm 0.09$ & $1.05 \pm 0.10$ & 0.5 \\
\hline $\mathrm{pHR}, \%$ predicted & $88.4 \pm 10.3$ & $85.9 \pm 12.3$ & 0.3 \\
\hline $\mathrm{VE} / \mathrm{VCO}_{2}$ & $29.8 \pm 3.4$ & $32.2 \pm 4.5$ & 0.003 \\
\hline $\mathrm{FEV}_{1}, \%$ predicted & $102 \pm 18$ & $93 \pm 22$ & 0.022 \\
\hline Breathing reserve, $1 / \mathrm{min}$ & $52 \pm 23$ & $42 \pm 20$ & 0.021 \\
\hline $\mathrm{AT}, \%$ predicted $\mathrm{pVO}_{2}$ & $65 \pm 13$ & $62 \pm 17$ & 0.2 \\
\hline SVI rest, $\mathrm{ml} / \mathrm{m}^{2}$ & $35.0 \pm 8.5$ & $31.3 \pm 8.7$ & 0.033 \\
\hline SVI exercise, $\mathrm{ml} / \mathrm{m}^{2}$ & $44.9 \pm 9.3$ & $38.9 \pm 9.3$ & 0.002 \\
\hline Increase SVI exercise/SVI rest, \% & $31.4 \pm 17.5$ & $28.0 \pm 24.5$ & 0.5 \\
\hline AVA index, $\mathrm{cm}^{2} / \mathrm{m}^{2}$ & $0.43 \pm 0.10$ & $0.46 \pm 0.11$ & 0.26 \\
\hline $\mathrm{Vmax}, \mathrm{m} / \mathrm{s}$ & $4.24 \pm 0.69$ & $3.79 \pm 0.76$ & 0.002 \\
\hline Mean gradient, $\mathrm{mm} \mathrm{Hg}$ & $43.8 \pm 14.9$ & $35.9 \pm 14.9$ & 0.007 \\
\hline Age, years & $72.7 \pm 8.3$ & $71.8 \pm 9.7$ & 0.6 \\
\hline Atrial fibrillation & $2(5.3)$ & $14(15.2)$ & 0.15 \\
\hline COPD & $1(2.6)$ & $20(21.7)$ & 0.007 \\
\hline$\beta$-Blocker & $7(18.4)$ & $28(30.4)$ & 0.2 \\
\hline
\end{tabular}

Values are presented as $\mathrm{n}(\%)$ and mean $\pm \mathrm{SD} . \mathrm{AT}=$ Anaerobic threshold. tors of when $\mathrm{pVO}_{2}$ would be less than $83 \%$ of the predicted value. Demographic, comorbidity, echocardiographic variables and CPX variables were used. Continuous variables were dichotomised by quartiles and medians, and the linearity assumption was tested by grouping patients by quartile. Multivariate models were constructed using stepwise forward regression starting with the variables yielding the lowest $\mathrm{p}$ values. The Hosmer-Lemeshow goodness-offit test was applied and we recognised significance with $p<0.05$.

\section{Results}

Of 145 eligible patients, 14 declined participation; thus, a total of 131 were included. The patient baseline characteristics are presented in table 1. CPX was successfully performed on 130 patients (99.2\%), and IGR was successfully performed on $129(98.5 \%)$ at rest and 116 (88.5\%) during submaximal exercise. On average, exercise IGR was performed beyond the anaerobic threshold at $73 \%$ of the patients' predicted pHR and at $83 \%$ of the patients' obtained pHR. The $\mathrm{VO}_{2}$ and $\mathrm{O}_{2}$ pulse trajectories were obtained for 129 (98.5\%) participants. On average, the study population was able to exercise to an $\mathrm{R}$ of $1.05( \pm 0.10)$, achieve $86.7 \%( \pm 11.7)$ of the predicted $\mathrm{pHR}$, achieve $96.8 \%( \pm 22.2)$ of the predicted $\mathrm{pVO}_{2}$, and reach $108.8 \%( \pm 24.2)$ of the predicted $\mathrm{pO}_{2}$ pulse. Abnormal $\mathrm{O}_{2}$ pulse and $\mathrm{VO}_{2}$ trajectories were observed in 17 partici- pants (13.2\%), and these patients exhibited significantly higher $\mathrm{R}$ and mean gradients across the aortic valve, suggesting that abnormal trajectories are associated with severe aortic stenosis and high effort. Those who were referred as equivocal symptomatic had lower $\mathrm{pVO}_{2}$ values at similar efforts ( $\mathrm{pHR}$ and $\mathrm{R}$ ), lower $\mathrm{FEV}_{1}$ values (although on average in the normal range), higher $\mathrm{VE} /$ $\mathrm{VCO}_{2}$ values and lower breathing reserves (table 2). Furthermore, they had lower stroke volumes at rest and during exercise and lower $\mathrm{pO}_{2}$ pulse/ $\mathrm{Hb}$ indexes (reflecting the stroke volume at peak exercise), but were able to increase SVI from rest to exercise similar to the asymptomatic group. Lower stroke volume explains why there may be lower gradients in the equivocal symptomatic group but a similar AVA index between the two groups.

\section{Predictors of Decreased $\mathrm{pVO}_{2}$}

A subnormal $\mathrm{pVO}_{2}$ (i.e. $<83 \%$ of the predicted value) was observed in 34 (26.1\%) of the participants. The univariate and multivariate predictors of subnormal $\mathrm{pVO}_{2}$ are presented in table 3. Unsurprisingly, the multivariate independent predictors were decreased cardiac function (stroke volume) and pHR (effort) during exercise, decreased pulmonary function $\left(\mathrm{FEV}_{1}\right)$ and decreased ventilation/pulmonary blood flow efficiency $\left(\mathrm{VE} / \mathrm{VCO}_{2}\right)$. Although the $\mathrm{pO}_{2}$ pulse/ $\mathrm{Hb}$ index reflects stroke volume, we 
preferred to use SVI determined by IRG in the analysis because the former is derived from $\mathrm{pVO}_{2}$. Mean gradient, Vmax, AVA index, E/e' (as continuous or divided by the upper/lower quartiles or median), BNP > ULN and presence of diabetes also were not univariate predictors.

\section{Decision of Treatment according to Evaluation of CPX} and 1-Year Outcome

Results of the CPX indicated haemodynamic compromise in 18 patients (11 with symptoms during CPX, 7 without), 5 of whom did not have subnormal $\mathrm{pVO}_{2}$ values according to our prespecified definition, but did have important exercise-limiting symptoms (angina, $\mathrm{n}=3$; dizziness and discomfort, $\mathrm{n}=2$ ). After angiogram and evaluation by an independent heart team, 15 had AVR, 2 with concomitant coronary surgery. Two patients refused valve replacement, and 1 of these had valve replacement after a hospitalisation with heart failure. One patient was declined AVR by the heart team because of high operative risk and minor symptoms. The characteristics and CPX outcomes of these 18 patients, compared to those who followed an initial conservative strategy, are presented in figure 1 and table 4 .

\section{Reproducibility}

Coefficients of variability for the test-retest analysis that was performed using 15 study patients were 5.4, 4.6 and $5.7 \%$ for $\mathrm{pVO}_{2}, \mathrm{pO}_{2}$ pulse and $\mathrm{pHR}$, respectively. The kappa $(\kappa)$ values for abnormal $\mathrm{O}_{2}$ pulse trajectory and for abnormal $\mathrm{O}_{2}$ pulse and $\mathrm{VO}_{2}$ trajectories were 0.70 and 1.0 , respectively. The coefficient of variability for SVI during submaximal exercise was $14.2 \%$, and there was a mean difference of $-3.3( \pm 6.9) \mathrm{ml} / \mathrm{m}^{2}$ between the SVI determined using IGR during submaximal exercise and that determined using the $\mathrm{pO}_{2}$ pulse/Hb index.

\section{Symptoms during CPX, Systolic Blood Pressure and ST Segment Response and CPX Outcomes}

Of our 130 patients, 25 (19.2\%) experienced symptoms during the exercise test. The CPX outcomes for these patients, classified as referred for AVR or treated with a conservative strategy, are illustrated in figure 2.

Compared to all other patients, their mean $\mathrm{pVO}_{2}$ values were lower ( $84 \%$ of the predicted value), but they achieved a mean pHR of $85 \%$ of the predicted value and a mean $\mathrm{R}$ of 1.07 , indicating sufficient effort. Their mean $\mathrm{VE} / \mathrm{VCO}_{2}$ was above normal at 34 . Of these 25 patients, those treated with a conservative strategy $(\mathrm{n}=14)$ were characterised by low mean $\mathrm{pVO}_{2}$ values but normal mean $\mathrm{pO}_{2}$ pulse values ( $98.4 \%$ of the predicted value). They also
Table 3. Univariate and multivariate predictors of $\mathrm{pVO}_{2}<83 \%$ of the predicted

Odds ratio $(95 \% \mathrm{CI}) \quad \mathrm{p}$ value
Univariate

SVI-exercise $\left(\mathrm{ml} / \mathrm{m}^{2}\right)$

SVI-exercise $<35 \mathrm{ml} / \mathrm{m}^{2}$

$\mathrm{O}_{2}$ pulse $/ \mathrm{Hb}$ index $\left(\mathrm{ml} / \mathrm{m}^{2}\right)$

$\mathrm{R}<1$

pHR (\% predicted)

$\mathrm{FEV}_{1}$ (\% predicted)

$\mathrm{FEV}_{1}<80 \%$ predicted

$\mathrm{VE} / \mathrm{VCO}_{2}$

$\mathrm{VE} / \mathrm{VCO}_{2}>32$

Hypertension

COPD

Atrial fibrillation

On $\beta$-blocker

Zva $>5.5 \mathrm{~mm} \mathrm{Hg} / \mathrm{ml} / \mathrm{m}^{2}$

Age (years)

$\mathrm{Sa}(\mathrm{cm} / \mathrm{s})$

\section{Multivariate}

SVI-exercise $\left(\mathrm{ml} / \mathrm{m}^{2}\right)$

pHR (\% predicted)

$\mathrm{FEV}_{1}$ (\% predicted)

$\mathrm{VE} / \mathrm{VCO}_{2}$

SVI-exercise $<35 \mathrm{ml} / \mathrm{m}^{2}$

pHR (\% predicted)

$\mathrm{FEV}_{1}<80 \%$ predicted

$\mathrm{VE} / \mathrm{VCO}_{2}>32$

$\begin{array}{lr}1.09(1.03-1.14) & 0.001 \\ 5.10(2.13-12.24) & <0.001 \\ 1.10(1.04-1.16) & <0.001 \\ 2.88(1.21-6.85) & 0.017 \\ 1.06(1.02-1.10) & 0.002 \\ 1.07(1.04-1.11) & <0.001 \\ 6.14(2.42-15.56) & <0.001 \\ 0.80(0.71-0.89) & <0.001 \\ 6.83(2.77-16.89) & <0.001 \\ 2.87(1.18-6.97) & 0.02 \\ 6.81(2.50-18.53) & <0.001 \\ 3.39(1.16-9.89) & 0.026 \\ 2.08(0.89-4.82) & 0.087 \\ 2.97(1.28-6.90) & 0.011 \\ 1.04(0.99-1.09) & 0.060 \\ 1.50(1.03-2.17) & 0.034\end{array}$

$1.09(1.01-1.17)$

0.022

$1.06(1.01-1.12) \quad 0.031$

$1.07(1.03-1.11) \quad<0.001$

$0.80(0.69-0.93) \quad 0.005$

$5.59(1.80-17.35) \quad 0.003$

$1.07(1.02-1.12) \quad 0.008$

$5.01(1.56-16.04) \quad 0.007$

$6.38(2.03-20.02) \quad 0.002$
Odds ratios were calculated for decreasing SVI, $\mathrm{O}_{2}$ pulse $/ \mathrm{Hb}$ index, $\mathrm{pHR}, \mathrm{FEV}_{1}, \mathrm{VE} / \mathrm{VCO}_{2}$ and $\mathrm{Sa}$.

Table 4. Characteristics and CPX results in those referred for AVR and with conservative strategy

\begin{tabular}{lccl}
\hline & $\begin{array}{l}\text { Recommended } \\
\text { AVR } \\
(\mathrm{n}=18)\end{array}$ & $\begin{array}{l}\text { Conservative } \\
\text { strategy } \\
(\mathrm{n}=112)\end{array}$ & $\begin{array}{l}\mathrm{p} \\
\text { value }\end{array}$ \\
\hline Age, years & $69 \pm 10$ & $72 \pm 9$ & 0.2 \\
Male/female ratio & 5.0 & 1.5 & 0.07 \\
COPD, \% & 6 & 18 & 0.3 \\
Atrial fibrillation, \% & 11 & 13 & 1 \\
Diabetes, \% & 17 & 12 & 0.5 \\
NYHA class I, \% & 44 & 54 & 0.6 \\
BNP $>$ ULN, \% & 39 & 26 & 0.2 \\
$\beta$-Blocker treatment, \% & 22 & 28 & 0.8 \\
Vmax, m/s & $4.2 \pm 0.7$ & $3.9 \pm 0.8$ & 0.06 \\
Vmax $>4 \mathrm{~m} / \mathrm{s}, \%$ & 56 & 40 & 0.3 \\
Mean gradient, $\mathrm{mm} \mathrm{Hg}$ & $44 \pm 16$ & $37 \pm 15$ & 0.07 \\
AVA index, cm ${ }^{2} / \mathrm{m}^{2}$ & $0.39 \pm 0.09$ & $0.46 \pm 0.11$ & 0.005 \\
AVA index $<0.6 \mathrm{~cm}^{2} / \mathrm{m}^{2}, \%$ & 100 & 88 & 0.2 \\
Sa, cm $/ \mathrm{s}$ & $4.6 \pm 1.6$ & $5.1 \pm 1.2$ & 0.2 \\
E/e' & $12.8 \pm 4.2$ & $13.4 \pm 5.1$ & 0.6 \\
\hline
\end{tabular}

Cardiology 2016;133:147-156

DOI: $10.1159 / 000441292$ 


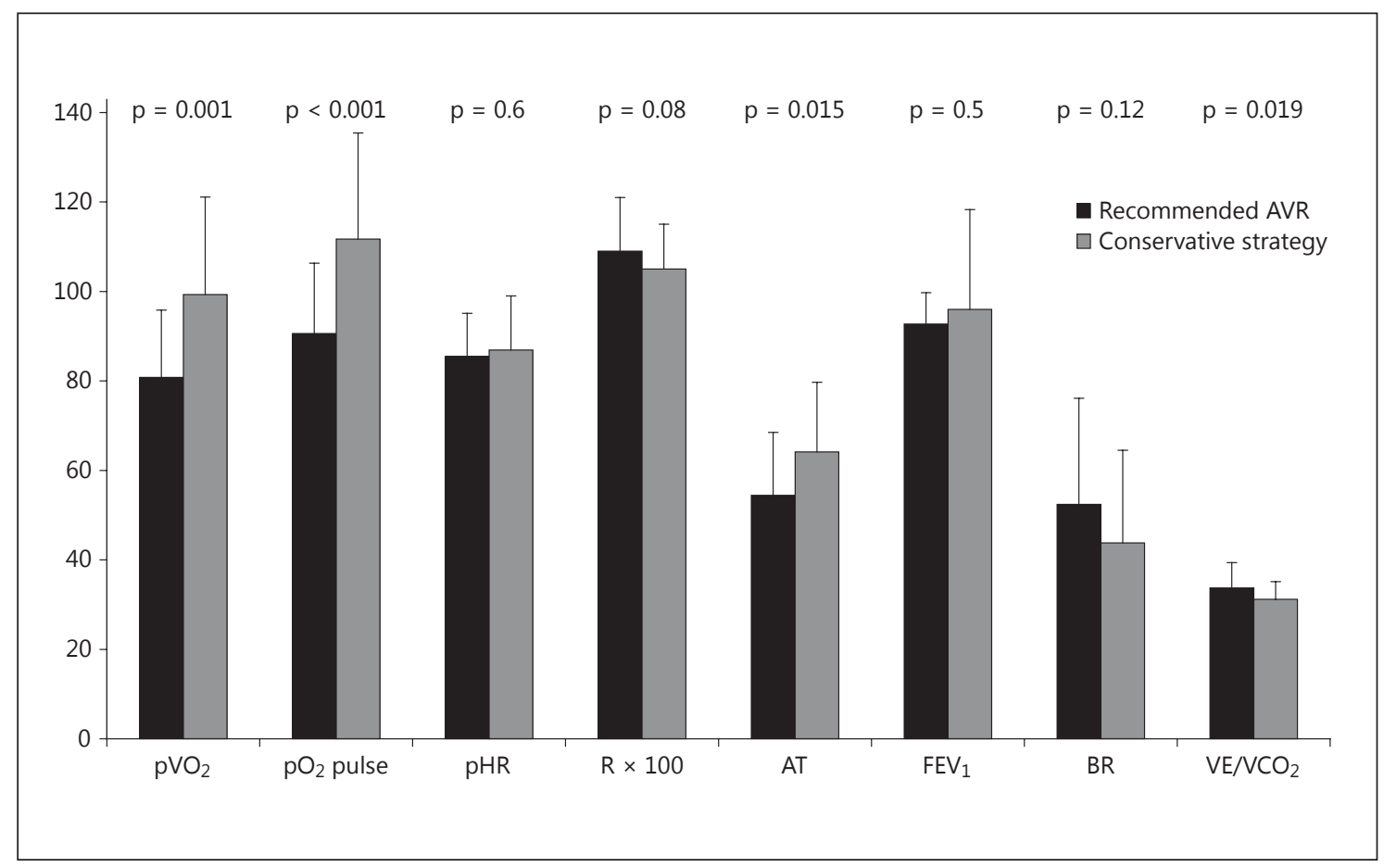

Fig. 1. CPX results in those recommended $\operatorname{AVR}(n=18)$ versus an initial conservative strategy $(n=112) \cdot p V O_{2}$, $\mathrm{pO}_{2}$ pulse, $\mathrm{pHR}$ and $\mathrm{FEV}_{1}$ are in percent of predicted; AT (anaerobic threshold) is in percent of predicted $\mathrm{pVO}_{2}$. Mean values are shown and bars represent $\mathrm{SD} . \mathrm{BR}=$ Breathing reserve.

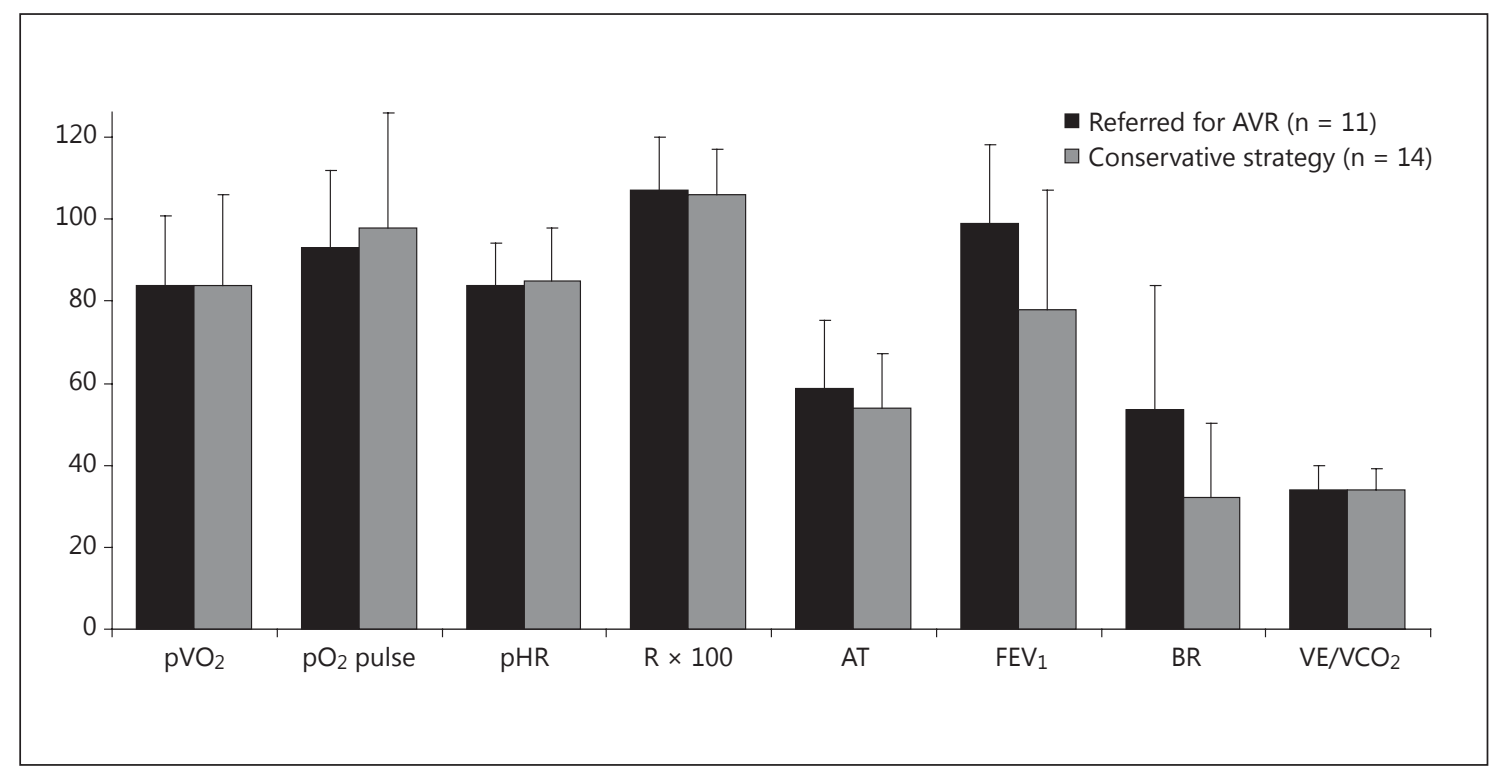

Fig. 2. $\mathrm{CPX}$ results in those with symptoms during $\mathrm{CPX}$. $\mathrm{pVO}_{2}, \mathrm{pO}_{2}$ pulse, $\mathrm{pHR}$ and $\mathrm{FEV}_{1}$ are in percent of predicted. AT (anaerobic threshold) is in percent of predicted $\mathrm{pVO}_{2}$. Mean values are shown and bars represent SD. $\mathrm{p}=0.048$ for $\mathrm{FEV}_{1} ; \mathrm{p}>0.05$ for other comparisons. The multiple testing and rather low subject numbers (small subgroups) should be considered. $\mathrm{BR}=$ Breathing reserve. 


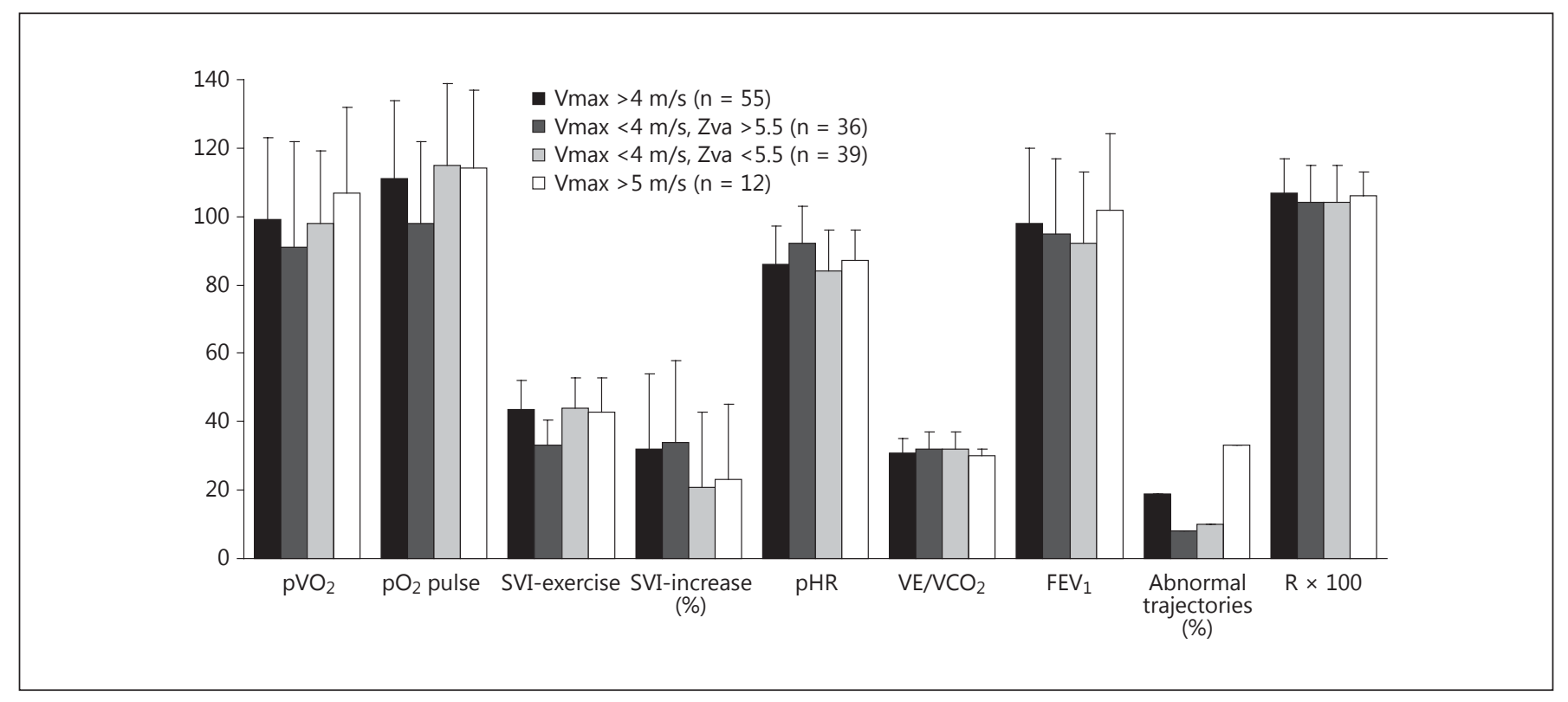

Fig. 3. CPX outcomes according to peak gradient across the aortic valve (Vmax) and $\mathrm{Zva}$. $\mathrm{pVO}_{2}, \mathrm{pO}_{2}$ pulse, $\mathrm{pHR}$ and $\mathrm{FEV}_{1}$ are in percent of predicted SVI in $\mathrm{ml} / \mathrm{m}^{2}$. SVI increase is the percent increase from SVI-rest to SVI-exercise. Group mean values and SD (bars) are presented if not otherwise indicated. Those with Vmax $\geq 4 \mathrm{~m} / \mathrm{s}$ showed slightly lower $\mathrm{VE} / \mathrm{VCO}_{2}(\mathrm{p}=0.032)$ compared to those with $\mathrm{V} \max <4 \mathrm{~m} / \mathrm{s}$. Those with $\mathrm{V} \max <4 \mathrm{~m} / \mathrm{s}$ and Zva $>5.5$

had low $\mathrm{FEV}_{1}$ and breathing reserves, and $57 \%$ were NYHA class II or above. Half had BNP > ULN. Among the 25 patients with symptoms during CPX, those who were treated with a conservative strategy had less severe aortic stenoses (yet were considered severe nonetheless), with a mean AVA index of 0.49 versus $0.39 \mathrm{~cm}^{2} / \mathrm{m}^{2}$ (for the difference, $95 \%$ CI $\left.0.09-0.19 \mathrm{~cm}^{2} / \mathrm{m}^{2} ; \mathrm{p}=0.01\right) \mathrm{com}$ pared to those who were referred for AVR. Both groups had a mean age of 69 years.

Thirty-five participants (26.9\%) exhibited a decrease or increase in systolic blood pressure of less than $20 \mathrm{~mm}$ $\mathrm{Hg}$ during exercise. Their achieved percentages of predicted $\mathrm{pVO}_{2}$ and $\mathrm{pO}_{2}$ pulse values were $101 \%( \pm 24)$ and $114 \%( \pm 26)$, respectively, and the frequency of abnormal $\mathrm{O}_{2}$ pulse and $\mathrm{VO}_{2}$ trajectories (11.9\%) observed in these participants was not significantly different from that seen in all other patients. A similar result was found for the 12 patients (9.2\%) who exhibited ST depressions greater than $2 \mathrm{~mm}$.

\section{Chronic Obstructive Pulmonary Disease}

Patients with a history of COPD reached a lower percentage of their predicted $\mathrm{pVO}_{2}$ values (80.6 vs. $99.9 \%$; $\mathrm{mm} \mathrm{Hg} / \mathrm{ml} / \mathrm{m}^{2}$ showed lower $\mathrm{pO}_{2}$ pulse $[\mathrm{p}=0.003$ (excluding the 16 patients with atrial fibrillation, $\mathrm{p}=0.016)]$, SVI-exercise $[\mathrm{p}<$ $0.001(\mathrm{p}<0.001)]$, higher $\mathrm{pHR}[\mathrm{p}=0.004(\mathrm{p}=0.077)]$ and a trend toward lower $\mathrm{pVO}_{2}[\mathrm{p}=0.083(\mathrm{p}=0.10)]$ compared to the other groups. No differences between these groups were observed for the other parameters displayed in this figure.
95\% CI -29.2 to $-9.5 \%$; $<<0.001$ ), pHR values (80.4 vs. $87.9 \%$; $95 \% \mathrm{CI}-12.9$ to $-2.1 \%$; $\mathrm{p}=0.007)$ and breathing reserves (30.9 vs. $48.0 ; 95 \% \mathrm{CI}-26.8$ to $-7.5 ; \mathrm{p}=0.001$ ) and exhibited higher values for $\mathrm{VE} / \mathrm{VCO}_{2}$ (33.5 vs. 31.1; 95\% CI 2.1-12.9; $\mathrm{p}=0.02$ ) compared to those without COPD. The mean values for the indices of stroke volume (absolute and achieved percentages of the predicted $\mathrm{pO}_{2}$ pulse, $\mathrm{pO}_{2}$ pulse/ $\mathrm{Hb}$ index and SVI from IGR) were in the normal range and not statistically different from those without pulmonary disease. The same was found for mean R, Vmax and AVA index.

\section{Peak Gradient and Zva Values, and CPX Outcomes}

The results of CPX and IGR when patients were grouped according to Vmax and Zva are presented in figure 3. The group that had Vmax less than $4 \mathrm{~m} / \mathrm{s}$ and high Zva showed significantly lower values for the indices of stroke volume during exercise than patients in the other three groups. This was confirmed using two methods and separate exercise tests (i.e. lower achievement of the predicted $\mathrm{pO}_{2}$ pulse and lower SVI from IGR during submaximal exercise, $p<0.003$ for both). The frequency of atrial fibrillation was higher among the high Zva group 
Table 5. NYHA classification and achieved percent of predicted $\mathrm{pVO}_{2}$

\begin{tabular}{llll}
\hline NYHA & $\mathrm{pVO}_{2}$ & & \\
\cline { 2 - 4 } & $\begin{array}{l}<83 \% \text { of } \\
\text { predicted }\end{array}$ & $\begin{array}{l}\geq 83 \text { and }<100 \% \text { of } \\
\text { predicted }\end{array}$ & $\begin{array}{r}\geq 100 \% \text { of } \\
\text { predicted }\end{array}$ \\
\hline Class I & $12(18)$ & $21(31)$ & $35(51)$ \\
Class II & $13(29)$ & $19(42)$ & $13(29)$ \\
Class III & $10(59)$ & $3(18)$ & $4(23)$ \\
\hline
\end{tabular}

Values are presented as $\mathrm{n}(\%) . \kappa=0.208$ for NYHA class and achieved percent of predicted $\mathrm{pVO}_{2}$.

$(25 \% ; p=0.014)$, but the pattern was identical when patients with atrial fibrillation were excluded from the analysis.

The group that had Vmax greater than $5 \mathrm{~m} / \mathrm{s}$ had CPX results in the normal to supranormal range. This finding may indicate selection bias because it is likely that only those with a high functional capacity and a Vmax greater than $5 \mathrm{~m} / \mathrm{s}$ would have been deemed asymptomatic or equivocal symptomatic. A trend toward a higher frequency of abnormal trajectories $(\mathrm{p}=0.053)$ was noted. Age, $\mathrm{Sa}$, $\mathrm{E} / \mathrm{e}^{\prime}$, frequency of BNP > ULN, COPD and $\beta$-blocker use were not different between the groups.

\section{Functional Classification and CPX Outcomes}

The association between NYHA classification and $\mathrm{pVO}_{2}$ is presented in table 5. Although a logical trend in the tabulation was noted, many patients were misclassified by NYHA versus objective measurement of functional capacity $\left(\mathrm{pVO}_{2}\right)$ as the gold standard, and the $\kappa$ was low (0.21).

\section{Discussion}

\section{Feasibility, Reproducibility and Safety}

The feasibility of CPX was nearly $100 \%$ in this patient group, which had a mean age of 72.1 years and in general had an AVA index less than $0.6 \mathrm{~cm}^{2} / \mathrm{m}^{2}$, which is regarded as a severe aortic stenosis [1], and most were deemed equivocal symptomatic. Hence, the study population was generally older and presented with some symptoms and significant aortic stenoses. This feasibility is clearly higher than that described for exercise echocardiography in patients deemed able to exercise [12]. The $4-6 \%$ coefficients of variability obtained for CPX in the test-retest analyses were similar to or better than those observed in healthy subjects and in patients with heart failure $[13,14]$. Due to the high feasibility and low coefficients of variability, CPX appears to be a usable tool for serial testing.

The safety of CPX and a CPX-guided strategy was high, with no adverse events during the test and no deaths from aortic stenosis or coronary disease during the 12-month follow-up. This observation included patients who were aged over 70 years, judged NYHA class II or III, suffering from COPD, and/or those who had Vmax values greater than $5 \mathrm{~m} / \mathrm{s}, \mathrm{BNP}>\mathrm{ULN}, \mathrm{Vmax}$ values less than $4 \mathrm{~m} / \mathrm{s}$ but high Zva values, symptoms during exercise testing or lack of systolic blood pressure increases of at least $20 \mathrm{~mm} \mathrm{Hg}$ or ST depression by more than $2 \mathrm{~mm}$ during testing. Accordingly, if the CPX did not indicate haemodynamic compromise, according to our definitions, a conservative strategy seemed safe and adequate at least up to 1 year, despite observations that otherwise would point to a symptomatic status or a status of haemodynamic compromise.

\section{Information on Haemodynamic and \\ Exercise Physiology}

On average, our study population exhibited $\mathrm{pVO}_{2}$ and $\mathrm{pO}_{2}$ pulse values in the normal range. The SVIs, as determined by IGR, increased from baseline to submaximal exercise, and the frequency of patients with abnormal trajectories was not high. Thus, our patients were generally able to increase and maintain stroke volume during exercise. This observation is in contrast with previous reports that used patients with similar degrees of aortic stenoses, but indicated that increases in cardiac output occurred only via increases in heart rate [15]. It agrees, however, with a more recent study that included 37 patients with asymptomatic aortic stenoses [5]. We found a trend toward more frequent abnormal trajectories in those who had values for Vmax greater than $5 \mathrm{~m} / \mathrm{s}$, suggesting that with such severe aortic stenosis a significant decrease in stroke volume at peak exercise may be more common.

Patients with low values for Vmax and high values for Zva were characterised by low resting stroke volumes with similar indices for left ventricular systolic (Sa) and diastolic function (E/e') when compared to other groups (also when patients with atrial fibrillation were excluded), leading to lower stroke volumes at submaximal exercise and lower values for $\mathrm{pO}_{2}$ pulse. However, SVIs increased from baseline to exercise. Accordingly, CPX with IGR indicated that in general the culprit of decreased stroke volume at peak exercise and exercise capacity was not the aortic stenosis in these patients. Thus, interventions that increase SVI, such as exercise training and medical treat- 
ment that improves afterload and diastolic filling time might be beneficial in patients who have low gradients across the valve and high Zva. This is a notion that requires further study. Similarly, for those deemed equivocal symptomatic by the referring physician, lower $\mathrm{pVO}_{2}$ values could be explained by lower resting stroke volumes, which also explains their seemingly less severe aortic stenoses as determined from gradients across the valve, and by less optimal respiratory responses to exercise.

\section{Information beyond Conventional Exercise Testing, $\mathrm{pVO}_{2}$ and Functional Classification}

Patients with moderate or severe aortic stenosis and with an NYHA II classification or with decreased exercise capacity and/or symptoms during exercise using conventional exercise testing are likely to be deemed either symptomatic from aortic stenosis from haemodynamic compromise or as difficult to assess. In this study, patients with a truly decreased exercise capacity (i.e. decreased $\mathrm{pVO}_{2}$ ) were logically predicted independently not only by lower stroke volume during exercise, but also by non- or only semi-cardiac factors such as effort (pHR and R), $\mathrm{FEV}_{1}$ and $\mathrm{VE} / \mathrm{VCO}_{2}$. Accordingly, a decreased exercise capacity $\left(\mathrm{pVO}_{2}\right)$ is not always caused by significant haemodynamic compromise from the aortic stenosis. The favourable 1-year outcome shows that, if CPX reveals normal values for $\mathrm{pO}_{2}$ pulse and/or decreased values for $\mathrm{FEV}_{1}$ and breathing reserve or a low effort $(\mathrm{R}<1)$, significant haemodynamic compromise from the aortic stenosis was not likely present, even in those with symptoms and decreased $\mathrm{pVO}_{2}$.

\section{Limitations}

Our results may not apply to all patients with aortic stenoses. The inclusion criteria may favour asymptomatic patients with rather high gradients and those with medium gradients, but a low AVA index and some symptoms, functional limitations or comorbidities. However, it is in such patients that assessment is difficult and information about the components of cardiopulmonary physiology during exercise may be important.

Patients who were deemed unable to exercise were not included in the study. However, patients with aortic stenoses and high frailty are seldom considered for AVR if they are asymptomatic or equivocal symptomatic.

The exercise SVI was determined just after the anaerobic threshold, where the SVI peaks. Thereafter, a gradual decline is normal [6]. If a patient showed more than the usual decline in SVI, which might be observed with the onset of severe haemodynamic compromise, this would be reflected in decreased $\mathrm{pVO}_{2}$ and $\mathrm{pO}_{2}$ pulse or abnormal trajectories.

The choice of a cut-off at $\mathrm{pVO}_{2}$ at $83 \%$ of the predicted and $\mathrm{pO}_{2}$ pulse at $95 \%$ of the predicted provided sufficient effort $(R>1)$ may not necessarily be the optimal value. However, the use of these three criteria ensures a decreased cardiac output and stroke volume at peak exercise, at a level well beyond the respiratory compensation point. A recent study showed that patients with aortic stenosis and a $\mathrm{pVO}_{2}$ less than $80 \%$ of the predicted had an adverse prognosis [16].

Although their $\mathrm{pVO}_{2}$ values were not subnormal according to our criteria, a few patients were categorised as having pathological tests because of symptoms only. These 5 patients had symptoms that were considered clearly limiting. We think that a patient who theoretically had a previous supranormal $\mathrm{pVO}_{2}$, who clearly had limiting symptoms and who had a current $\mathrm{pVO}_{2}$ at, for example, $87 \%$ of the predicted value at high $\mathrm{R}, \mathrm{pHR}$ and normal $\mathrm{FEV}_{1}$, should be suspected of having haemodynamic compromise, and that the evaluation of symptoms is part of CPX. It should be noted that the majority of patients (14 of 25) with symptoms during CPX followed a conservative strategy.

As our study was not randomised, we cannot conclude that the patients who were referred for AVR based on the evaluation of CPX results improved their prognosis by AVR, only that a CPX-guided strategy was safe up to 1 year. An observational period of 1 year may be regarded too short. However, this represents the longest interval used for reassessment in such patients, and was also the observation period used in previous important studies [3].

\section{Conclusions}

In patients with aortic stenosis who are difficult to assess by standard methods, CPX showed high feasibility and reproducibility, and gave data on haemodynamics and exercise physiology beyond that obtained from standard methods. A CPX-guided treatment strategy was safe up to 1 year. 


\section{References}

1 Bonow RO, Carabello BA, Chatterjee K, et al: 2006 guidelines for the management of patients with valvular heart disease. J Am Coll Cardiol 2008;52:e1-e142.

2 Otto CM, Burwash IG, Legget ME, et al: Prospective study of asymptomatic valvular aortic stenosis. Circulation 1997;95:2262-2270.

3 Das P, Rimington H, Chambers JB: Exercise testing to stratify risk in aortic stenosis. Eur Heart J 2005;26:1309-1313.

4 Bonow RO: Exercise hemodynamics and risk assessment in asymptomatic aortic stenosis. Circulation 2012;126:803-805.

5 Rajani R, Rimington H, Chambers JB: Treadmill exercise in apparently asymptomatic patients with moderate or severe aortic stenosis; relationship between cardiac index and revealed symptoms. Heart 2010;96:689-695.

6 Wasserman K, Hansen JE, Sue DY, et al: Principles of Exercise Testing and Interpretation: Including Pathophysiology and Clinical Applications, ed 4. Philadelphia, Lippincott, Williams and Wilkins, 2005, pp 69, 146, 167, 173, 199.
7 Lang CC, Karlim P, Haythe J, et al: Noninvasive measurement of cardiac output during exercise by inert gas rebreathing technique: a new tool for heart failure evaluation. J Am Coll Cardiol 2005;46:1779-1781.

8 Stringer W, Hansen J, Wassserman K: Cardiac output estimated non-invasively from oxygen uptake $\left(\mathrm{VO}_{2}\right)$ during exercise. J Appl Physiol 1997;82:908-912.

9 Guazzi M, Adams V, Conraads V, et al: Clinical recommendations for cardiopulmonary exercise testing data assessment in specific patient populations. Circulation 2012;126: 2261-2274

10 Bruch C, Stypmann J, Grude M, et al: Tissue Doppler imaging in patients with moderate to severe aortic valve stenosis: clinical usefulness and diagnostic accuracy. Am Heart J 2004; 148:696-702.

11 Hachicha Z, Dumesnil JG, Bogaty P, et al: Paradoxical low-flow, low-gradient severe aortic stenosis despite preserved ejection fraction is associated with higher afterload and reduced survival. Circulation 2007;115:2856-2864.

12 Lancellotti P, Magne J, Donal E, et al: Determinants and prognostic significance of exercise pulmonary hypertension in asymptomatic severe aortic stenosis. Circulation 2012; 126:851-859.
13 Keteyian SJ, Brawner CA, Ehrman JK, Ivanhoe R, Boehmer JP, Abraham WT; PEERLESS-HF Trial Investigators: Reproducibility of peak oxygen uptake and other cardiopulmonary exercise parameters: implications for clinical trials and clinical practice. Chest 2010; 138:950-955.

14 Bensimhon DR, Leifer ES, Ellis SJ, et al; HFACTION Trial Investigators: Reproducibility of peak oxygen uptake and other cardiopulmonary exercise testing parameters in patients with heart failure (from the Heart Failure and A Controlled Trial Investigating Outcomes of Exercise Training). Am J Cardiol 2008;102:712-717.

15 Otto C, Bonow RO: Valvular Heart Disease, ed 3. Philadelphia, Saunders, 2009, p 132.

16 Dhoble A, Enriquez-Serrano M, Kopecky SL, et al: Cardiopulmonary responses to exercise and its utility in patients with aortic stenosis. Am J Cardiol 2014;113:1711-1716. 